\title{
PENINGKATAN KEMAMPUAN MENYIMAK TEKS CERPEN MELALUI MODEL PEMBELAJARAN COOPERATIVE LEARNING TIPE JIGSAW
}

\author{
Sri Sulastri \\ Program Studi Pendidikan dan Sastra Indonesia \\ Fakultas Sastra, Universitas Muslim Indonesia \\ Email: srisulastriburhan@gmail.com
}

\begin{abstract}
Abstrak: Aktivitas menyimak memerlukan sebuah ingatan untuk memahami sebuah bacaan. Dari ingatan tersebut siswa dapat menggunakan sebuah informasi dan pesan untuk menuangkan dalam sebuah tulisan. Penelitian ini bertujuan untuk Penelitian ini bertujuan untuk mendeskripsikan proses pembelajaran menyimak cerpen dengan menggunakan metode cooperative learning, serta kemampuan menyimak cerpen dengan menggunakan metode cooperative learning pada siswa kelas XI SMA Negeri 18 Makassar. Jenis penelitian yang digunakan dalam penelitian ini adalah Penelitian Tindakan Kelas (PTK). Penelitian ini menggunakan metode cooperative learning. Subek penelitian ini adalah keseluruhan siswa kelas XI IPA 2 SMA Negeri 18 Makassar yang berumlah 35 siswa. Teknik pengumpulan data yang digunakan adalah merencanakan tindakan, melaksanakan tindakan yang telah direncanakan, malakukan observasi, membuat refleksi atas tindakan pada siklus I oleh peneliti dan guru, dan dokumentasi. Hasil penelitian menunjukkan bahwa pembelajaran menggunakan metode cooperative learning dapat meningkatkan aktivitas dan perhatian siswa, terbukti dari rerata partisipasi siklus I, dan siklus II. Hasil tes menunjukkan bahwa menggunakan model cooperative learning dapat meningkatkan kemampuan menyimak cerpen pada siswa kelas XI SMA Negeri 18 Makassar.
\end{abstract}

Kata Kunci: Menyimak cerpen; metode cooperative learning; cerpen

\section{PENDAHULUAN}

Di Indonesia aktivitas menyimak dapat ditingkatkan melalui pendidikan, khususnya dalam pembelajaran Bahasa Indonesia. Mata pelajaran Bahasa Indonesia dimulai sejak Sekolah Dasar (SD) dari kelas satu hingga jenjang perguruan tinggi. Akan tetapi, pada tingkatan terampil dibutuhkan waktu dan usaha yang lama. Menurut Muhibbin Syah (2014) kata keterampilan memiliki definisi kegiatan yang berhubungan dengan urat-urat syaraf dan otototot yang lazimnya tampak dalam kegiatan jasmaniah. Pendapat lain dikemukakan oleh Reber (Muhibbin Syah, 2014) yang menyatakan bahwa keterampilan adalah kemampuan melakukan pola-pola tingkah laku yang kompleks dan tersusun rapi secara mulus dan sesuai dengan keadaan untuk mencapai hasil tertentu. Secara garis besar, seseorang dapat dikatakan terampil apabila dapat menyelesaikan tugas dengan cepat dan benar.

Di Indonesia aktivitas menyimak dapat ditingkatkan melalui pendidikan, khususnya dalam pembelajaran Bahasa Indonesia. Mata pelajaran Bahasa Indonesia dimulai sejak Sekolah Dasar (SD) dari kelas satu hingga jenjang perguruan tinggi. Akan tetapi, pada tingkatan terampil dibutuhkan waktu dan usaha yang lama. Menurut Muhibbin Syah (2014) kata keterampilan memiliki definisi kegiatan yang berhubungan dengan urat-urat syaraf dan otototot yang lazimnya tampak dalam kegiatan jasmaniah. Pendapat lain dikemukakan oleh Reber (Muhibbin Syah, 2014) yang menyatakan bahwa keterampilan adalah kemampuan melakukan pola-pola tingkah laku yang kompleks dan tersusun rapi secara mulus dan sesuai dengan keadaan untuk mencapai hasil tertentu. Secara garis besar, seseorang dapat dikatakan terampil apabila dapat menyelesaikan tugas dengan cepat dan benar.

Pada Sekolah Menengah Atas keterampilan siswa dalam menyimak cerpen masih rendah. Rendahnya kemampuan siswa dalam menyimak cerpen dipengaruhi oleh dua faktor, yaitu faktor internal dan faktor eksternal. Faktor internal datang dari diri siswa, yaitu siswa kurang berminat dalam pembelajaran 
menyimak cerpen. Rendahnya minat siswa terhadap pembelajaran menyimak cerpen menyebabkan siswa menjadi kurang antusias selama proses pembelajaran menyimak cerpen dan siswa cenderung pasif selama proses tanya jawab mengenai materi unsur intrinsik cerpen. Selain itu, faktor internal lain yaitu kurangnya konsentrasi siswa pada saat guru menjelaskan unsur intrinsik cerpen. Pada kenyataannya beberapa siswa mengobrol dengan teman sebangkunya dan mengabaikan perintah untuk memperhatikan penjelasan dari guru. Hal tersebut mengakibatkan siswa belum bisa memahami unsur intrinsik cerpen dengan baik, khususnya pada tahapan alur cerpen, yaitu siswa belum bisa membedakan antara konflik dan klimaks cerpen. Selain itu, kurangnya konsentrasi siswa pada saat menyimak cerpen juga menyebabkan kegiatan pembelajaran terhambat. Pembelajaran menyimak cerpen belum menggunakan media pembelajaran yang sesuai sehingga siswa bosan terhadap cerpen yang disimak yang mengakibatkan konsentrasi siswa berkurang.

Arti kata simak atau menyimak dalam Kamus Besar Bahasa Indonesia (KBBI) adalah mendengar (memperhatikan) baik-baik apa yang diucapkan atau dibaca orang.

$$
\text { Menyimak memiliki makna }
$$

mendengarkan atau memperhatikan baik-baik apa yang dikatakan orang lain. Jelas faktor kesengajaan dalam kegiatan menyimak cukup besar, lebih besar daripada mendengarkan karena dalam kegiatan menyimak ada usaha memahami apa yang disimaknya sedangkan dalam kegiatan mendengarkan tingkatan pemahaman belum dilakukan (Sutari, 2013).

$$
\text { Hermawan (2012) mengemukakan }
$$
bahwa menyimak berbeda dengan mendengar. Menyimak bersifat aktif, sedangkan mendengar bersifat pasif, spontan, dan tidak selektif. Menyimak tidak hanya merupakan aktifitas mendengarkan tetapi merupakan sebuah proses memilih dari sekian banyak rangsangan di sekitar kita.

Menurut Logan (dalam Tarigan 2018), tujuan menyimak beraneka ragam, antara lain: (1) menyimak untuk belajar, yaitu untuk memperoleh pengetahuan dari ujaran pembicara; (2) menyimak untuk menikmati keindahan audial, yaitu menyimak dengan menekankan pada penikmatan terhadap sesuatu dari materi yang diujarkan atau yang diperdengarkan; (3) menyimak untuk mengevaluasi, yaitu menyimak dengan maksud agar dia menilai apa yang disimak; (4) menyimak untuk mengapresiasi materi simakan, yaiitu menyimak agar dapat menikmati serta menghargai apa-apa yang disimaknya; (5) menyimak untuk mengkomunikasikan ide-idenya sendiri. Orang menyimak dengan maksud agar dapat mengkomunikasikan ide, gagasan, maupun perasaannya kepada orang lain dengan lancar dan tepat; (6) menyimak dengan maksud dan tujuan dapat membedakan bunyi-bunyi dengan tepat; (7) menyimak untuk memecahkan secara kreatif dan analisis; dan (8) menyimak untuk meyakinkan dirinya terhadap suatu masalah atau pendapat yang diragukan.

Selain itu, Hunt (dalam Tarigan 2018) juga berpendapat tentang tujuan menyimak antara lain: (1) menyimak untuk memperoleh informasi (2) menyimak agar menjadi lebih efektif dalam hubungan antarpribadi dalam kehidupan sehari-hari (3) menyimak untuk mengumpulkan data (4) menyimak agar mendapatkan responsi yang tepat terhadap segala sesuatu yang didengar.

Tarigan (2018) mengklasifikasikan jenis menyimak sebagai berikut:

\section{Menyimak Ekstensif}

Menyimak ekstensif adalah kegiatan menyimak mengenai hal-hal yang lebih umum dan lebih bebas terhadap suatu ujaran. Penggunaan yang paling dasar adalah mengungkap atau mengingat kembali bahan 
yang telah dikenal atau diketahui dalam suatu lingkungan baru dengan cara yang baru.

\section{Menyimak Intensif}

Menyimak intensif diarahkan pada suatu kegiatan yang jauh lebih diawasi, dikontrol terhadap suatu hal tertentu. Salah satu cara yang sangat sederhana utnuk melatih jenis menyimak ini adalah menyuruh siswa menyimak tanpa teks tulis, dengan cara sekali atau dua kali, kemudian memberikan kepada mereka suatu bagian yang mengandung beberapa penghubung kalimat dan memberikan kepada mereka teks-teks tertulis dengan mengosongkan tempat penghubung-penghubung kalimat itu berada. Tugas mereka adalah mengisinya tanpa menyimak pada pita rekaman lagi.

3. Menyimak Sosial

Menyimak sosial (social listening) atau menyimak konversasional (conversasional listening) biasanya berlangsung dalam situasi-situasi social tempat orang-orang bercengkerama mengenai hal-hal yang menarik perhatian semua orang dan saling mendengarkan satu sama lain untuk membuat response yang pantas dan memperlihatkan perhatian yang wajar terhadap apa yang dikemukakan oleh seorang rekan.

4. Menyimak Sekunder

Menyimak sekunder (secondary listening) adalah menyimak secara kebetulan dan secara ekstensif, misalnya menyimak musik yang mengiringi ritme atau tarian rakyat, menikmati musik sementara ikut berpartisipasi dalam kegiatan tertentu misalnya melukis, membuat sketsa, dll.

5. Menyimak Estetik/ Apresiatif

Menyimak estetik (aestetic listening) ataupun yang disebut juga menyimak apresiatif (appreciational listening) adalah menyimak sebuah karya misalnya menyimak musik, puisi, prosa atau drama yang dibacakan.

6. Menyimak Kritis
Menyimak kritis (critical listening) adalah menyimak yang di dalamnya terlihat kekurangannya serta ketidak telitiannya yang akan diamati, misalnya menyimak untuk memahami makna petunjuk konteks, menyimak kebiasaan ujaran yang tepat, kata, pemakaian kata dan unsur kalimat lainnya, dll.

Jadi, menyimak cerpen adalah kegiatan mendengarkan cerita pendek dengan penuh perhatian disertai pemahaman, apresiasi, dan interpretasi untuk memperoleh pesan dan informasi serta menanggapi hal yang terkandung di dalam cerpen yang telah disimak dan diharapkan memperoleh inspirasi yang dapat melahirkan inspirasinya.

\section{METODE}

Jenis penelitian ini merupakan Penelitian Tindakan Kelas (PTK) (Classroom Action Research). Kemmis \& Tagrat (dalam Budhi Setiawan, 2017) menyatakan bahwa Action Research adalah suatu bentuk penelitian yang bersifat reflektif yang dilakukan oleh pelaku dalam masyarakat sosial dan bertujuan untuk memperbaiki pekerjaan, memahami pekerjaan, serta situasi di mana pekerjaan ini dilakukan. Penelitian Tindakan Kelas PTK merupakan studi yang sistematis yang dilakukan dalam upaya memperbaiki praktik-praktik dalam pendidikan dengan melakukan tindakan praktis serta refleksi dari tindakan tersebut. Proses pelaksanaan penelitian tindakan dilakukan dalam suatu rangkaian siklus yang berkelanjutan. Setiap langkah terdiri dari empat tahap yaitu perencanaan tindakan (planning), pelaksanaan tindakan (acting), pengamatan (observing), dan refleksi (reflecting). Berikut ini adalah visualisasi tahap-tahap tersebut:

1. Planning (perencanaan)

2. Acting (tindakan)

3. Observing (pengamatan)

4. Reflecting (refleksi) 
Penelitian ini dilaksanakan di SMA Negeri 18 Makassar. Sekolah ini terletak di Kompleks Mangga Tiga Permai Daya, Paccerakang, Kecamatan Biringkanaya, Kota makassar, Sulawesi Selatan.

Penelitian ini dilaksanakan selama satu bulan yaitu; pada tanggal 15 Juli s/d 15 Agustus 2019

Subjek dalam penelitian ini adalah siswa kelas XI IPA 2 SMA Negeri 18 Makassar tahun ajaran 2018/2019. Jumlah siswa di kelas tersebut adalah 35 siswa, terdiri dari 19 siswa putra dan 16 siswa putri.

Ada tiga sumber data penting yang dijadikan sebagai sasaran penggalian dan pengumpulan data serta informasi dalam penelitian ini. Sumber data tersebut meliputi : tempat dan peristiwa, informan, dan dokumen.

Tempat dan peristiwa yang menjadi sumber data dalam penelitian ini, yaitu kegiatan bercerita yang berlangsung di dalam kelas dengan menggunakan metode kooperatif tipe jigsaw.

Informan, dalam penelitian ini menggunakan informan guru Bahasa Indonesia kelas XI IPA 2 SMA Negeri 18 Makassar.

Dokumen yang berupa rekaman aktivitas komunikatif pembelajaran kemampuan menyimak cerpen siswa, hasil tes siswa, buku pendamping pelajaran Bahasa dan Sastra Indonesia, buku dongeng/cerita anak-anak bergambar, rancangan pedoman pembelajaran yang dibuat peneliti dan guru, silabus yang ditetapkan oleh pihak sekolah, serta hasil angket yang diisi oleh siswa.

\section{HASIL DAN PEMBAHASAN}

Kelas yang digunakan dalam penelitian adalah kelas XI IPA 2 yang terdiri atas 35 siswa. Kegiatan awal yang dilakukan peneliti yaitu mengadakan observasi awal untuk mengetahui keadaan sebenarnya serta mencari informasi untuk menemukan berbagai kendala yang dihadapi sekolah dalam proses pembelajaran Bahasa Indonesia, khususnya pada peningkatan kemampuan menyimak teks cerpen. Hal ini menyebabkan kemampuan siswa dalam pembelajaran kemampuan menyimak teks cerpen belum mencapai Kriteria Ketuntasan Minimal (KKM), sehingga kemampuan siswa dalam kompetensi dasar menyimak cerpen masih sangat sulit.

Tabel 4.1 Hasil Penilaian Menyimak Cerpen Siswa Prasiklus

\begin{tabular}{|c|c|c|c|}
\hline No & Nama & Nilai & Tingkat keberhailan \\
\hline 1. & 001 & 60 & Rendah \\
\hline 2. & 002 & 56 & Rendah \\
\hline 3. & 003 & 60 & Rendah \\
\hline 4. & 004 & 76 & Tinggi \\
\hline 5. & 005 & 62 & Rendah \\
\hline 6. & 006 & 50 & Rendah \\
\hline 7. & 007 & 60 & Rendah \\
\hline 8. & 008 & 72 & Sedang \\
\hline 9. & 009 & 60 & Rendah \\
\hline 10. & 0010 & 62 & Rendah \\
\hline 11. & 0011 & 76 & Tinggi \\
\hline 12. & 0012 & 60 & Rendah \\
\hline 13. & 0013 & 62 & Rendah \\
\hline 14. & 0014 & 60 & Rendah \\
\hline 15. & 0015 & 76 & Tinggi \\
\hline 16. & 0016 & 70 & Sedang \\
\hline 17. & 0017 & 72 & Sedang \\
\hline 18. & 0018 & 54 & Rendah \\
\hline 19. & 0019 & 60 & Rendah \\
\hline 20. & 0020 & 60 & Rendah \\
\hline 21. & 0021 & 76 & Tinggi \\
\hline 22. & 0022 & 50 & Rendah \\
\hline 23. & 0023 & 60 & Tinggi \\
\hline 24. & 0024 & 60 & Rendah \\
\hline 25. & 0025 & 62 & Rendah \\
\hline 26. & 0026 & 76 & Sedang \\
\hline 27. & 0027 & 60 & Tinggi \\
\hline 28. & 0028 & 72 & Sedang \\
\hline 29. & 0029 & 60 & Tinggi \\
\hline 30. & 0030 & 76 & Tinggu \\
\hline 31. & 0031 & 72 & Sedang \\
\hline 32. & 0032 & 62 & Rendah \\
\hline 33. & 0033 & 62 & Rendah \\
\hline 34. & 0034 & 62 & Rendah \\
\hline 35. & 0035 & 50 & Rendah \\
\hline \multicolumn{2}{|c|}{ Total } & 2224 & \\
\hline
\end{tabular}


Jumlah nilai yang diperoleh siswa

$$
\begin{gathered}
\text { Jumlah siswa } \\
=\frac{2224}{35} \times 100 \% \\
=63
\end{gathered}
$$

Berdasarkan hasil pengamatan yang diperoleh, bahwa pada tes yang dilakukan tindakan nilai nilai terendah 50 sebanyak 3 siswa, dan nilai tertinggi adalah 76 sebanyak 5 siswa, sedangkan nilai rata-rata yang diperoleh adalah 63. Dapat disimpulkan bahwa kemampuan menyimak cerpen siswa sebelum dilakukanya tindakan termasuk ke dalam kategori kurang.

Tabel 4.2 Hasil Penelitian Menulis Cerpen

\begin{tabular}{|c|c|c|c|}
\hline No. & Nama & Nilai & Tingkat Keberhasilan \\
\hline 1. & 001 & 62 & Rendah \\
\hline 2. & 002 & 60 & Rendah \\
\hline 3. & 003 & 62 & Rendah \\
\hline 4. & 004 & 60 & Rendah \\
\hline 5. & 005 & 78 & Tinggi \\
\hline 6. & 006 & 60 & Rendah \\
\hline 7. & 007 & 63 & Rendah \\
\hline 8. & 008 & 78 & Tinggi \\
\hline 9. & 009 & 74 & Sedang \\
\hline 10. & 0010 & 74 & Sedang \\
\hline 11. & 0011 & 82 & Rendah \\
\hline 12. & 0012 & 62 & Tinggi \\
\hline 13. & 0013 & 78 & Sedang \\
\hline 14. & 0014 & 76 & Tinggi \\
\hline 15. & 0015 & 82 & Tinggi \\
\hline 16. & 0016 & 78 & Sedang \\
\hline 17. & 0017 & 76 & Rendah \\
\hline 18. & 0018 & 60 & Rendah \\
\hline 19. & 0019 & 62 & Rendah \\
\hline 20. & 0020 & 62 & Tinggi \\
\hline 21. & 0021 & 82 & Rendah \\
\hline 22. & 0022 & 62 & Sedang \\
\hline 23. & 0023 & 76 & Sedang \\
\hline 24. & 0024 & 74 & Sedang \\
\hline 25. & 0025 & 76 & Sedang \\
\hline 26. & 0026 & 76 & Rendah \\
\hline 27. & 0027 & 62 & Sedang \\
\hline 28. & 0028 & 74 & Sedang \\
\hline 29. & 0029 & 76 & Rendah \\
\hline 30. & 0030 & 82 & Tinggi \\
\hline 31. & 0031 & 74 & Sedang \\
\hline
\end{tabular}
Siswa Siklus 1

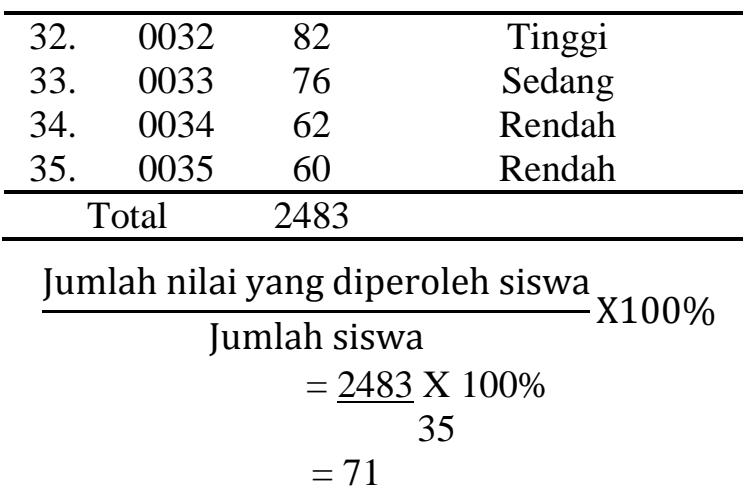

Berdasarkan hasil pengamatan selama proses pembelajaran menunjukkan sikap siswa dalam mengikuti pembelajaran Bahasa Indonesia dengan menggunakan metode cooperative learning tipe jigsaw belum sepenuhnya tampak. Meskipun sudah dijelaskan, masih ada siswa yang belum mampu mengekspresikan gagasan, pendapat, pikiran, dan menceritakan kembali cerpen yang telah dibacakan peneliti. Sehingga nilai yang diperoleh siswa pada siklus I belum menunjukkan perubahan yang cukup berarti. Dengan nilai rata-rata mencapai 71 , siswa yang memperoleh nilai $<75$ (KKM) ada 14 siswa atau $40 \%$ dan yang memperoleh nilai $>75$ (KKM) yaitu 21 siswa atau $60 \%$.

Tabel 4.3 Hasil Penelitian Cerpen Siklus II

\begin{tabular}{cccc}
\hline No & Nama & Nilai & Tingkat Keberhasilan \\
\hline 1. & 001 & 82 & Tinggi \\
2. & 002 & 82 & Tinggi \\
3. & 003 & 63 & Sedang \\
4. & 004 & 76 & Tinggi \\
5. & 005 & 84 & Tinggi \\
6. & 006 & 63 & Rendah \\
7. & 007 & 76 & Sedang \\
8. & 008 & 84 & Tinggi \\
9. & 009 & 92 & Tinggi \\
10. & 0010 & 84 & Tinggi \\
11. & 0011 & 92 & Tinggi \\
12. & 0012 & 76 & Sedang \\
13. & 0013 & 92 & Tinggi \\
14. & 0014 & 82 & Tinggi \\
15. & 0015 & 92 & Tinggi \\
16. & 0016 & 92 & Tinggi \\
17. & 0017 & 84 & Tinggi \\
18. & 0018 & 63 & Rendah \\
\hline
\end{tabular}




\begin{tabular}{lccc}
\hline 19. & 0019 & 82 & Tinggi \\
20. & 0020 & 63 & Rendah \\
21. & 0021 & 92 & Tinggi \\
22. & 0022 & 84 & Tinggi \\
23. & 0023 & 78 & Tinggi \\
24. & 0024 & 92 & Tinggi \\
25. & 0025 & 82 & Tinggi \\
26. & 0026 & 92 & Sedang \\
27. & 0027 & 76 & Tinggi \\
28. & 0028 & 92 & Sedang \\
29. & 0029 & 76 & Tinggi \\
30. & 0030 & 92 & Tinggi \\
31. & 0031 & 82 & Rendah \\
32. & 0032 & 63 & Tinggi \\
33. & 0033 & 82 & Tinggi \\
34. & 0034 & 76 & Sedang \\
35. & 0035 & 84 & Tinggi \\
\hline \multicolumn{5}{c}{ Total } & 2876 & \\
\hline Jumlah nilai yang diperoleh siswa X100\% \\
\hline \multicolumn{5}{c}{ Jumlah siswa } \\
\multicolumn{5}{c}{ = 2876 X 100\% } \\
= 82
\end{tabular}

Berdasarkan hasil pengamatan selama proses pembelaaran menulis cerpen dengan menggunakan metode cooperative learnig tipe jigsaw menunjukkan hampir sepenuhnya mengalami perubahan dari siklus sebelumnya siswa sudah memahami dan merasa senang mengikuti pelajaran bahasa Indonesia khususnya menyimak teks cerpen sehingga siswa terlihat sangat antusias ketika peneliti membacakan cerpen di depan kelas.

Tabel 4.4 Hasil Menulis Cerpen Siswa pada Pretes, Siklus I, dan Siklus II

\begin{tabular}{ccccc}
\hline No & Nama & Pretes & Siklus I & Siklus II \\
\hline 1. & 001 & 60 & 62 & 82 \\
2. & 002 & 56 & 60 & 82 \\
3. & 003 & 60 & 62 & 76 \\
4. & 004 & 76 & 60 & 92 \\
5. & 005 & 62 & 78 & 84 \\
6. & 006 & 50 & 60 & 63 \\
7. & 007 & 60 & 63 & 76 \\
8. & 008 & 72 & 78 & 84 \\
9. & 009 & 60 & 74 & 92 \\
10. & 0010 & 62 & 74 & 84 \\
\hline
\end{tabular}

\begin{tabular}{|c|c|c|c|c|}
\hline 11. & 0011 & 76 & 82 & 92 \\
\hline 12. & 0012 & 60 & 62 & 76 \\
\hline 13. & 0013 & 62 & 78 & 92 \\
\hline 14. & 0014 & 60 & 76 & 82 \\
\hline 15. & 0015 & 76 & 82 & \\
\hline 16. & 0016 & 70 & 78 & \\
\hline 17. & 0017 & 72 & 76 & 84 \\
\hline 18. & 0018 & 54 & 60 & 63 \\
\hline 19. & 0019 & 60 & 62 & 82 \\
\hline 20. & 0020 & 60 & 62 & 63 \\
\hline 21. & 0021 & 76 & 82 & 92 \\
\hline 22. & 0022 & 50 & 62 & 84 \\
\hline 23. & 0023 & 60 & 76 & 78 \\
\hline 24. & 0025 & 60 & 74 & 92 \\
\hline 25. & 0025 & 62 & 76 & 82 \\
\hline 26. & 0026 & 72 & 76 & 92 \\
\hline 27. & 0027 & 60 & 62 & 76 \\
\hline 28. & 0028 & 72 & 74 & 92 \\
\hline 29. & 0029 & 60 & 76 & 76 \\
\hline 30. & 0030 & 76 & 82 & 92 \\
\hline 31. & 0031 & 72 & 74 & 82 \\
\hline 32. & 0032 & 62 & 82 & 63 \\
\hline 33. & 0033 & 62 & 76 & 82 \\
\hline 34. & 0034 & 62 & 62 & 76 \\
\hline 35. & 0035 & 50 & 60 & 84 \\
\hline \multicolumn{2}{|c|}{ Rata-rata \% } & $31 \%$ & $57 \%$ & $86 \%$ \\
\hline
\end{tabular}

Berdasarkan tabel di atas, dapat membuktikan adanya peningkatan yang signifikan. Pada hasil pretes hanya $31 \%$ siswa yang mencapai nilai KKM. Setelah masuk pada siklus I telah terdapat 57\% siswa yang mencapai KKM. Sedangkan pada siklus II sebanyak $86 \%$. Hal ini telah memenuhi indikator keberhasilan yaitu $80 \%$ siswa memenuhi KKM dari sekolah yaitu 75 .

\section{KESIMPULAN}

Berdasarkan hasil analisis data dan pembahasan dapat disimpulkan tentang efektiftidaknya metode cooperative learning tipe jigsaw dalam pembelajaran menulis cerpen pada siswa kelas XI SMA Negeri 18 Makassar. Metode cooperative learning tipe jigsaw efektif diterapkan dalam pembelajaran menyimak teks cerpen siswa kelas XI SMA Negeri 18 Makassar. Hal ini tampak pada nilai yang diperoleh siswa sebelum menerapkan metode 
cooperative learning tipe jigsaw yang mengalami peningkatan setelah menerapkan metode cooperative learning tipe jigsaw.

\section{DAFTAR PUSTAKA}

Alwi, Hasan dan Dendy Sugono. 2013. Telaah Bahasa dan Sastra. Bandung: Pusat Bahasa dan Yayasan obor Indonesia.

Aminudin. 2016. Pengantar Apresiasi Karya Sastra. Bandung: Sinar Baru Argensindo.

Amri, Sofan \& Iif Khoiru Ahmadi. 2014. Konstruksi Pengembangan Pembelajaran (Pengaruh Terhadap Mekanisme dan Praktik Kurikulum). Jakarta: PT. Prestasi Pustakaraya.

Baribin, Raminah. 2017. Teori dan Apresiasi Prosa Fiksi. Semarang: IKIP Semarang Press.

Setiawan Budi 2017. "Penelitian Tindakan Kelas (PTK): Classroom Action Research". Makalah disampaikan pada acara Pelatihan Classroom Action Research bagi guru-guru SD, SMP, dan SMA Se-Kabupaten yang diselenggarakan oleh Forum Guru Kabupaten Sragen pada Senin, 20 Agustus 2017 di Aula Depdiknas Kabupaten Sragen.

Hermawan, Herry. 2012. Menyimak: Keterampilan Berkomunikasi yang Terabaikan. Yogyakarta: Graha Ilmu.

Ibrahim dan Nana Syaodih. 2003. Perencanaan Pengajaran. Jakarta: Depdikbut. Ice Sutari, dkk 2013. Menyimak. Jakarta: Depdikbut.

Lie, Anita. 2016. Cooperative Learning dan Memperaktekkan Cooperative Learning di ruang Kelas. Jakarta: Grasindo.

Milles, Mathew B. Dan Huberman, A. Michael. 2012. Analisis Data Kualitatif ( edisi terjemahan oleh tjeptjep Rohendi Rohidi). Jakarta: UI Pres.
Muhibbin Syah. 2014. Psikologi Pendidikan. Bandun: Rosdakarya.

Mulyati, Yeti dkk. 2012. Keterampilan Berbahasa Indonesia SD. Jakatra: Depdiknas.

Mansyur, Umar. 2016. Pemanfaatan Nilai kejujuran dalam Cerpen sebagai Bahan Ajar Berbasis Pendidikan Karakter. In Mengais Karakter dalam Sastra: HISKI Makassar (pp. 330-339).

Mansyur, Umar. 2018. Korelasi Minat Baca dengan Kemampuan Menulis Karya Tulis Ilmiah Mahasiswa Pendidikan Bahasa Indonesia UMI. Multilingual: Jurnal Kebahasaan dan Kesastraan, 17(1), 11-22.

Mansyur, U. (2018). Kiat dan Teknik Penulisan Skripsi bagi Mahasiswa. INA-Rxiv. https://doi.org/10.31227/osf.io/juds7

Nurgiyantoro, Burhan. 2013. Teori Pengkajian Fiksi. Yogyakarta: Gadah Mada University Press.

Nursisto. 2012. Ikhtisar Kesusastraan Indonesia. Jakarta: Rineka Cipta.

Sanjaya, Wina. 2007. Strategi Pembelajaran Berorientasi Standar Proses Pendidikan. Jakarta: Kencana.

Siswanto, Wahyudi.2017. Pengantar Teori Sastra. Jakarta: PT Grasindo.

Sudiman, Panuti. 2015. Memahami Cerita Rekaan. Jakarta: Pustaka Jaya.

Kemendikbut. 2016. Kamus Besar Bahasa Indonesia. Semarang: Widia Karya.

Sutari, dkk. 2013. Menyimak. Jakarta: Depdikbut.

Tarigan, Hendri Guntur. 2018. Menyimak: Sebagai Suatu Keterampilan Berbahasa. Bandung: Angkasa. 